\title{
Prologue: Gender Everywhere
}

In mid-December 2012, three weeks before I arrived in Delhi to conduct my first six months of ethnographic fieldwork in the emerging local hip hop scene, a ghastly crime was committed that went down in history as the Delhi gang rape. I find it too distressing to provide you with details about this merciless atrocity. The news media archives are full of it, should you want to take a look. Academic papers, books and BBC and Netflix documentaries, I heard, exist as well. The gang rape and the brutal murder of Jyoti Singh, who is now widely remembered as Nirbhaya, Fearless, triggered mass protests about women's safety and social justice in the city and around the globe, which revealed and fundamentally reshuffled the complex intersections between class, gender, sexuality, age, migration and mediatisation in early 21st-century Delhi history.

What's the relevance of gender in your research? Eva asked me this question over a home-made dinner on our rooftop terrace in South Delhi. The piercing look, the gentle raising of her eyebrows, which contextualised her question, discomforted me as I was happily chewing on a mouthful of delicious okras. Eva had just completed a master's degree in gender studies and was staying with me in Delhi during my ethnographic fieldwork for this research project in 2013. We had been together for several years already and loved each other very much and so I was very happy when Eva told me that she had secured a paid internship at a political non-governmental organisation in Delhi and was able to be with me during my ethnographic research. Throughout our relationship, Eva always took great efforts to make me aware of the pervasiveness of gender in society, and she kept pushing me to seriously think about gender in my research. So, on that night, over bhindi masala and chapattis, her voice became part of this book.

It doesn't play any role, I answered naïvely, assuming her question was just another iteration of her constant reminder that gender is generally a 
pervasive category. She shot back: Why not? I said: Well, there are hardly any women in my research. My answer to her follow-up question got trapped in the same conundrum which many cis heterosexual male academic colleagues and hip hop scholars get trapped in: gender is only relevant when there are women around. Men are somewhat genderless humans.

How can gender NOT play a role, when almost all of your participants are men? Boom. This hit me hard. Of course, she was right! The absence of women in a sociocultural formation does not translate into an absence of the category of gender; quite the opposite. In my unfeminist world view men were normalised and 'without gender'. From my normative viewpoint, gender would only become a relevant analytical category in a piece of research when women (or non-men) were taking part in it. In other words, I didn't see the wood for the trees - although this metaphor is perhaps unnecessarily phallic.

Yes. What are the social and cultural conditions that blatantly exclude women, non-heterosexual males and queer people from participating in hip hop cultures wherever they emerge? From New York City to Los Angeles, from Rio de Janeiro to Cape Town, from Marseille to Moscow, from Hong Kong to Delhi: everywhere we look we find straight men dominating the local hip hop scenes. Yes, surely, there is some progress here and there and women get together to form collectives and safe spaces in which they can rap, write, break, deejay and contest knowledge. To give just one recent example, the artistic collective Ladies of Rage from South Wales and Southwest England are actively promoting female-only hip hop spaces and whenever they enter male-dominated hip hop events, they do so with their large entourage of female hip hop artists to ensure that they have enough backing to call out and fight back against any discrimination that they might experience. And, of course, we mustn't forget that women played a key role during hip hop's inception in the late 1970s all through the 1980s and 1990s. We think of figures such as Lady Pink, MC Lyte, Roxanne Shante, Salt-N-Pepa or Queen Latifah. However, these old school heroines of hip hop, as well as the contemporary female protagonists of the culture, while relentlessly speaking out against misogyny and hyper-heterosexuality, were not (yet) powerful enough to challenge hip hop's hegemonic masculinity in its substance and normalise women in hip hop.

My experiences in India mirrored this extreme masculine bias of hip hop. Almost everyone I met was male. After my eye-opening conversation with Eva, four months into my fieldwork, I started actively looking out for female participants, which means that the few women that feature in this book overrepresent the actual number of women in the scene. Manmeet Kaur, a musician who will feature in Chapter 4 as well as in 
the epilogue, and Dizy, a graffiti writer who will feature in Chapter 5, were the only two women with whom I managed to conduct interviews. Apart from Manmeet and Dizy, I have met one b-girl, who, however, was not interested in becoming a participant of my research and I heard of another b-girl in Mumbai, Am-B, who, however, I never had a chance to meet personally. There were two further female graffiti writers in Delhi, who I met on collaborative painting sessions. One of them was Samsam, who you can see on the cover of this book.

In 2016, when the time came for me to think about a cover image for this book, I browsed through all the pictures I had taken in Delhi with my mobile phone camera. The image that shows Samsam rockin a spray can instantly struck a chord with me and I spontaneously contacted her on a social media platform, sent her the image and asked her if she would be happy for me to use her image as the cover for my book. She answered that she would be very honoured to see herself on the cover of a book on Delhi hip hop and allowed me to go forward with my plans. I was excited and thanked her. We did not hear from each other for over two years.

Then I received a message from her again just before signing the publishing contract for this book in 2018. Without any sugar-coating or phatic greetings, she got straight to the point:

I just noticed that the excerpt says narrative practices of young male etc :p why did you put me on the cover! Am super honoured to be on it of course!

If Eva's question complexified my ethnographic gaze, Samsam's question complexified the ways I represent my research participants. I did, of course, have a specific reason for using an image that depicted a woman rather than a man for the cover of my book and this reason had to do with my deliberate overrepresentation of women in this study. My 'own' bias was meant to even out something of the masculinist bias of hip hop that we find across the globe wherever the culture sets foot. But, could I tell her this?

I sat down and composed the following message, explaining (mansplaining?) myself:

Ha! That's such an interesting question! I thought about this a lot. So thanks for asking! Most people I hung out with in India were young heterosexual males. This category was so prevalent that I didn't even notice the insane gender imbalance in my study! By the time I realised it, I was already back in Europe. I regretted that I had been so blind and thought back to the females I did meet. Dizy, Manmeet Kaur and you. I have interviews with Dizy and Manmeet, but regrettably I never sat down 
with you properly. That's when I discovered this image and thought it was a) beautiful, b) flowy and therefore related to the trans theme of my writing and c) it did something to represent you. I write critically about gender and to degree sexuality in my thesis and therefore explicitly say that young men are the focus of discussion. Does that make sense? Sorry for the long explanation.

Samsam immediately wrote back.

Thank you for the long explanation! It makes perfect sense.

In early 2020, I had a chance to see Samsam again and we talked at length about masculinity, politics and life. It was during this conversation that I realised how much my positions on gender have changed from when I first embarked on this research in 2013 and it was then that I decided to include a prologue and epilogue 'on gender' in my book.

The interactions I had with Samsam and Eva, as well as with Dizy (Chapter 5) and Manmeet Kaur (Chapter 4, epilogue) were incredibly illuminating and fundamentally changed the ways I write about global hip hop. I began to rethink what it means be a cis, male, heterosexual researcher conducting ethnography in male-dominated cultural spaces. In Chapter 3, I say more about my own role as an ethnographic researcher who identifies, like most of my research participants, as well as most of my hip hop scholar colleagues, as a cis heterosexual male.

I decided against writing a chapter 'on gender' (although Chapter 7 comes close), not because I did not have enough materials to do so, but rather because I had too many. Gender was everywhere. No transcultural voice is genderless. I do not always explicitly talk about gender, because perhaps it would become tedious and I don't feel entitled to constantly remind ourselves of the feminist agenda, but I hope that this prologue will give readers enough food for thought to fill in the gaps for me and read gender into each and every analysis I provide in this book. I thus encourage my readers - you, whatever gender or sexuality you at times play with - to understand my 'own' voice on these pages also as fundamentally gendered and sexualised. Such a reading of this book's ethnographic hip hop linguistics might contribute to plotting a vision of a more inclusive hip hop culture where not only straight men, but also women, non-hetero men and queer people in urban India can make their voices and narratives heard on their 'own' terms. If Nirbhaya's death can teach us anything, then it is that we have to be more fearless when it comes to thinking, writing and talking about gender and sexuality. I hope that this book can be read with such fearlessness too. 